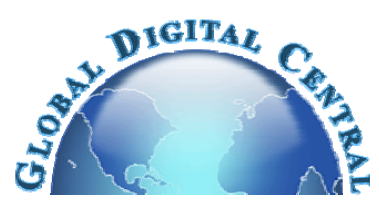

Frontiers in Heat and Mass Transfer

Available at www.ThermalFluidsCentral.org

\title{
JOULE HEATING AND THERMAL DIFFUSION EFFECTS ON MHD RADIATIVE AND CONVECTIVE CASSON FLUID FLOW PAST AN OSCILLATING SEMI-INFINITE VERTICAL POROUS PLATE
}

\author{
C. Veeresha, S. V. K. Varma ${ }^{\mathrm{a}}$, A .G. Vijaya Kumar ${ }^{\mathrm{b}}{ }^{* *}$, M. Umamaheswar ${ }^{\mathrm{c}}$ and M. C. Raju ${ }^{\mathrm{c}}$ \\ ${ }^{a}$ Department of Mathematics, Sri Venkateswara University, Tirupati-517 502, A.P, India. \\ ${ }^{b}$ Department of Mathematics, SAS, VIT University, Vellore-632014, TN, India. \\ ${ }^{c}$ Department of Humanities and Sciences, Annamacharya Institute of Technology and Sciences(Autonomous), Rajampet-516 126, A.P, \\ India.
}

\begin{abstract}
An analysis is performed to investigate the effects of Joule heating and thermal diffusion on unsteady, viscous, incompressible, electrically conducting MHD heat and mass transfer free convection Casson fluid flow past an oscillating semi-infinite vertical moving porous plate in the presence of heat source/sink and an applied transverse magnetic field. Initially it is assumed that the plate and surrounding fluid at the same temperature and concentration at all the points in stationary condition in the entire flow region. Thereafter a constant temperature is given to the plate hence the buoyancy effect is supporting the fluid to move in upward direction and is assumed that gravity is the only force which acts against to the flow direction. The governing flow is modeled in the form of partial differential equations with initial and boundary conditions. With suitable nondimensional quantities the governing non-linear partial differential equations obtained in dimensionless form, which are solved numerically with finite difference scheme. Numerical results for non-dimensional velocity, temperature and concentration as well as the skin-friciton, the rate of heat transfer and the rate of mass transfer studied for different physical parameters. The results show that the solutal boundary layer thickness of the fluid enhances with the increase of Prandtl number and the temperature is increased by an increase in the heat source by the fluid. The central reason behind this effect is that the heat source causes an increase in the kinetic energy as well as thermal energy of the fluid. The momentum and thermal boundary layers get thinner in case of heat source fluids.
\end{abstract}

Keywords: Casson fluid, MHD, free convection, thermal diffusion, Joule dissipation, heat and mass transfer.

\section{INTRODUCTION}

The study of Casson fluid flow on MHD free convection flows with heat transfer past a porous plate is attracting the attention of many researchers. Casson fluid in one of such fluid, this fluid has distinct features and is quite illustrious recently. Casson fluid model was introduced by Casson in 1959 for the prediction of the flow behavior of pigment-oil suspension. So for the flow, the shear stress magnetic of Casson fluid needs to exceed the yield shear stress, or else the fluid behaves as a rigid body. This kind of fluids can be marked as a purely viscous fluid with high viscosity. Casson model is based on a structure model of the interactive behavior of solid and liquid phases of two phase suspensions. Some famous examples of Casson fluid include jelly, sauce, tomato, honey, soup and concentrated fruit juice. Human blood can also be treated as Casson fluid due to the presence of several substances such as fibrinogen, protein, globulin in aqueous base plasma and human red blood cell. In all of the above studies the solutions of Casson fluid are either obtained by using approximate method or by any numerical scheme.

There are many cases in which the exact analytical solutions of Casson fluid are obtained. Vajravelu and Mukhopadhyay (2013) studied diffusion of chemically reactive species in Casson fluid flow over an unsteady permeable stretching surface. Das et al. (1996) analyzed Casson fluid flow in a pipe filled with a homogeneous porous medium.
Nadeem et al. (2013) considered MHD three-dimensional Casson fluid flow past a porous linearly stretching sheet. MHD flow of a Casson fluid over an exponentially shrinking sheet is addressed by Nadeem et al. (2012). Pramanik (2014) investigated Casson fluid flow and heat transfer past an exponentially porous stretching surface in the presence of thermal radiation. Hayat et al. (2012) discussed soret and Dufour effects on magneto hydrodynamic flow of Casson fluid. Mustafa et al. (2011) considered unsteady boundary layer flow of a Casson fluid due to an impulsively started moving flat plate. Numerical study of pulsatile MHD Non-Newtonian fluid flow with heat and mass transfer through a porous medium between two permeable parallel plates is addressed by Abdelna et al. (2006). Mukhopadhyay (2013) discussed effects of thermal radiation on Casson fluid flow and heat transfer over an unsteady stretching surface subjected to suction/blowing. Mukhopadhyay et al. (2013) considered Casson fluid flow over an unsteady stretching surface.

Shateyi et al. (2014) studied numerical analysis of MHD stagnation point flow of Casson fluid, heat and mass transfer over a stretching sheet. Boyd et al. (2007) discussed analysis of the Casson and Carreau-Yasuda non-Newtonian blood models in steady and oscillatory flows using the lattice Boltzmann method. Mernone et al. (2002) discussed a mathematical study of peristaltic transport of a

${ }^{*}$ Corresponding author. Email: vijayakumarag@,vit.ac.in 
Casson fluid. Bhattacharya (2009) studied boundary layer stagnationpoint flow of Casson fluid and heat transfer towards a shrinking/stretching sheet. Kumar and Varma (2011) studied thermal diffusion and radiation effects on unsteady MHD flow past an impulsively started exponentially accelerated vertical plate with variable temperature and variable mass diffusion.Casson fluid flow and heat transfer past an exponentially porous stretching surface in presence of thermal radiation is addressed by Pramanik (2013). Mustafa et al. (2014) discussed Stagnation-point flow and heat transfer of a Casson fluid towards a stretching sheet. Recently, Rushi Kumar et.al (2015) studied thermal diffusion effects on MHD heat and mass transfer flow past a moving vertical plate when the magnetic field relative to the fluid or to the plate.

\section{MATHEMATICAL FORMULATON}

In this problem, we have inestigated the effects of Joule heating and thermal diffusion on unsteady heat and mass trasnfer MHD Casson fluid flow past a vertical plate in the presence of Porous Medium with uniform temperature and mass concentration under the influence of applied transvers magnetic field. The $X^{*}$-axis is lay hold having an alignment, such as the top is directly above the bottom in upward direction and $y^{*}$ - axis is taken normal to it in the orientation of applied transverse magnetic field. Initially, it is assumed that the plate and surrounding fluid are at the same temperature and concentration in stationary condition for all the points in entire flow region. A uniform magnetic field of strength $B_{0}$ is applied perpendicular to the fluid flow direction.

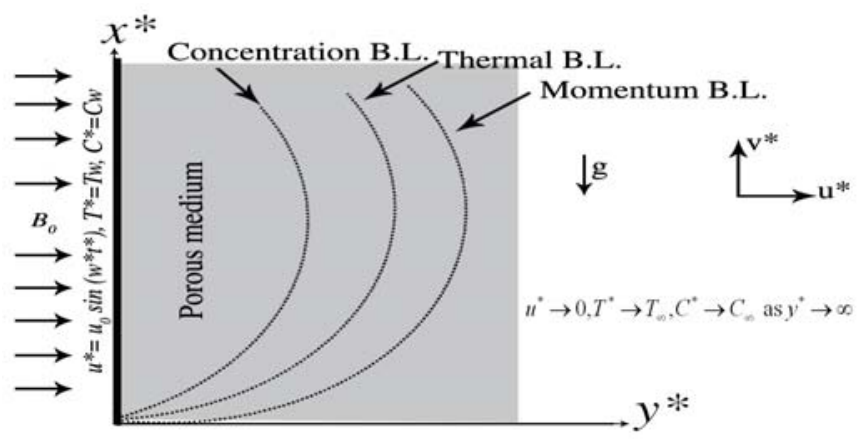

Fig. 1 Physical coordinate system

The induced magnetic field is neglected in comparison to the applied magnetic field as the magnetic Reynolds number of the flow is taken to be very small. At time $t^{*}>0$, the plate is given an oscillatory motion with velocity $u^{*}=u_{0} \sin \left(\omega^{*} t^{*}\right)$ in its own plane. At the same time, the plate temperature is raised to $T_{w}$ and also the mass is diffused from the plate uniformly with spices concentration $C_{w}$ as time advanced. The Joule dissipation is considered in the energy equation. The fluid is assumed to be gray emitting and absorbing radiation but non- scattering medium. All the fluid properties are assumed to be constant except the influence of the density variation with temperature in the body force term. Electric field and viscous dissipation effects are neglected. The constitutive equation for the Casson fluid can be written as (Mustafa eat al. [2011])

$\tau_{i j}= \begin{cases}2\left(\mu_{B}+\frac{P_{y}}{\sqrt{2 \pi}}\right) e_{i j} & \pi>\pi_{c}, \\ 2\left(\mu_{B}+\frac{P_{y}}{\sqrt{2 \pi_{c}}}\right) e_{i j} & \pi<\pi_{c}\end{cases}$

Where $\pi=e_{i j}, e_{i j}$ and $e_{i j}$ is the $(i, j)$ th component of the deformation rate, $\pi$ is the product of the component of deformation rate with itself, $\pi_{c}$ is a critical value of this product based on the non-
Newtonian model, $\mu_{B}$ is plastic dynamic viscosity of the nonNewtonian fluid and $\mathrm{P}_{\mathrm{y}}$ is yield stress of fluid. Under these assumptions, the equations that described the physical situation are given by

$$
\begin{aligned}
& \rho \frac{\partial u^{*}}{\partial t^{*}}=\mu_{\beta}\left(1+\frac{1}{\gamma}\right) \frac{\partial^{2} u^{*}}{\partial y^{* 2}}-\sigma B_{0}^{2} u^{*}-\frac{\mu \phi}{k_{1}} u^{*} \\
&+\rho g \beta\left(T^{*}-T_{\infty}\right)+\rho g \beta^{*}\left(C^{*}-C_{\infty}\right) \\
& \rho C_{p} \frac{\partial T^{*}}{\partial t^{*}}=k \frac{\partial^{2} T^{*}}{\partial y^{* 2}}+Q\left(T^{*}-T_{\infty}\right)-\frac{\partial q_{r}}{\partial y^{*}}+\sigma B_{0}^{2} u^{* 2} \\
& \frac{\partial C^{*}}{\partial t^{*}}=D \frac{\partial^{2} C^{*}}{\partial y^{* 2}}+D_{1} \frac{\partial^{2} T^{*}}{\partial y^{* 2}}
\end{aligned}
$$

Cogley et al. have shown that, in the optically thin limit for a non-gray gas near equilibrium, the radiative heat flux is represented by the following form:

$\frac{\partial q_{r}}{\partial{ }^{*}}=4\left(T^{*}-T_{\infty}\right) I$, where $I=\int K_{\lambda w} \frac{\partial e_{b \lambda}}{\partial T^{*}} d \lambda$

The initial and boundary conditions are

$$
\left.\begin{array}{rr}
t^{*}<0: u^{*} & =0, T^{*}=T_{\infty}, C^{*}=C_{\infty} \quad \text { for all } y^{*}<0 \\
t^{*} \geq 0: u^{*}=u_{0} \sin \left(w^{*} t^{*}\right), T^{*}=T_{w}, C^{*}=C_{w} \quad \text { at } y^{*}=0 \\
u^{*} \rightarrow 0, T^{*} \rightarrow T_{\infty}, C^{*} \rightarrow C_{\infty} & \text { as } y^{*} \rightarrow \infty
\end{array}\right\}
$$

On introducing the following non-dimensional quantities

$$
\begin{aligned}
& u=\frac{u^{*}}{u_{0}}, t=\frac{t^{*} u_{0}^{2}}{v}, \mathrm{y}=\frac{y^{*} u_{0}}{v}, \theta=\frac{T^{*}-T_{\infty}}{T_{w}-T_{\infty}}, \mathrm{C}=\frac{C^{*}-C_{\infty}}{C_{w}-C_{\infty}} \\
& G r=\frac{v g \beta\left(T_{w}-T_{\infty}\right)}{u_{0}^{3}}, G m=\frac{v g \beta\left(C_{w}-C_{\infty}\right)}{u_{0}^{3}}, S c=\frac{v}{D}, \mathrm{P}=\frac{v C_{p}}{k}, \\
& E=\frac{u_{0}^{2}}{C_{p}\left(T_{w}-T_{\infty}\right)}, Q=\frac{Q^{*} v}{\rho C_{p} u_{0}^{2}}, F=\frac{4 v I}{\rho C_{p} u_{0}^{2}}, S O=\frac{D\left(T_{w}-T_{\infty}\right)}{v\left(C_{w}-C_{\infty}\right)}
\end{aligned}
$$

In terms of the above non-dimension quantities, Equations (1)-(3) reduces to

$$
\begin{aligned}
& \frac{\partial u}{\partial t}=\left(1+\frac{1}{\gamma}\right) \frac{\partial^{2} u}{\partial y^{2}}-M u-\frac{1}{K} u+G r \theta+G m C \\
& \frac{\partial \theta}{\partial t}=\frac{1}{\operatorname{Pr}} \frac{\partial^{2} \theta}{\partial y^{2}}+Q \theta-F \theta+M E c u^{2} \\
& \frac{\partial C}{\partial t}=\frac{1}{S c} \frac{\partial^{2} C}{\partial y^{2}}+S O \frac{\partial^{2} \theta}{\partial y^{2}}
\end{aligned}
$$

The corresponding initial and boundary conditions are:

$$
\left.\begin{array}{rlrl}
t<0: u & =0, T=0, C=0 & & \text { for all } y<0 \\
t \geq 0: u & =\sin (w t), \theta=1, C=1 & & \text { at } y=0 \\
u & \rightarrow 0, T \rightarrow 0, C^{*} \rightarrow 0 & & \text { as } y \rightarrow \infty
\end{array}\right\}
$$

\section{METHOD OF SOLUTION}

Equations (5)-(7) are coupled non-linear partial differential equations and are to be solved by using the initial and boundary conditions (8). However exact solution is not possible for this set of equations and hence we solve these equations by finite-difference method. The equivalent finite difference schemes of equations for (5)-(7) are as follows: 


$$
\begin{aligned}
& \frac{u_{i, j+1}-u_{i, j}}{\Delta t}=\left(1+\frac{1}{\gamma}\right)\left(\frac{u_{i-1, j}-2 u_{i, j}+u_{i+1, j}}{(\Delta y)^{2}}\right)-M u_{i, j} \\
&-\frac{1}{K} u_{i, j}+G r \theta_{i, j}+G c C_{i, j} \\
& \frac{\theta_{i, j+1}-\theta_{i, j}}{\Delta t}= \frac{1}{\operatorname{Pr}}\left(\frac{\theta_{i-1, j}-2 \theta_{i, j}+\theta_{i+1, j}}{(\Delta y)^{2}}\right)+Q \theta_{i, j} \\
&-F \theta_{i, j}+M E c\left(u_{i, j}\right)^{2} \\
& \frac{C_{i, j+1}-C_{i, j}}{\Delta t}= \frac{1}{S c}\left(\frac{C_{i-1, j}-2 C_{i, j}+C_{i+1, j}}{(\Delta y)^{2}}\right) \\
&+S r\left(\frac{\theta_{i-1, j}-2 \theta_{i, j}+\theta_{i+1, j}}{(\Delta y)^{2}}\right)
\end{aligned}
$$

Here, index $\mathrm{i}$ refer to $\mathrm{y}$ and $\mathrm{j}$ to time. The mesh system is divided by taking $\Delta y=0.04$. From the initial condition in (8), we have the following equivalent:

$u(i, 0)=0, \theta(i, 0)=0, C(i, 0)=0$ for all $i$

The boundary conditions from (8) are expressed in finite-difference form as follows

$$
\begin{aligned}
& u(0, j)=1, \theta(0, j)=1, C(0, j)=1 \text { for all } j \\
& u\left(i_{\max }, j\right)=\sin \left(w^{*}(j-1) * \Delta t\right), \theta\left(i_{\max }, j\right)=1, C\left(i_{\max }, j\right)=1 \text { for all } j
\end{aligned}
$$

(Here $\mathrm{i}_{\max }$ was taken as 201)

First the velocity at the end of time step viz, $u(i, j+1),(i=1,201)$ is computed from (9) in terms of velocity, temperature and concentration at points on the earlier time-step. Then $\theta(i, j+1)$ is computed from (10) and $C(i, j+1)$ is computed from (11). The procedure is repeated until $\mathrm{t}=0.05$ (i.e. $\mathrm{j}=500$ ). During computation $\Delta \mathrm{t}$ was chosen as 0.0001 .

\section{Skin-friction:}

The skin-friction in non-dimensional form is given by

$$
\tau=-\left(1+\frac{1}{\gamma}\right)\left(\frac{d u}{d y}\right)_{y=0}, \text { where } \tau^{*}=\frac{\tau}{\rho u_{0}^{2}}
$$

\section{Rate of heat transfer:}

The dimensionless rate of heat transfer is given by

$N u=-\left(\frac{d \theta}{d y}\right)_{y=0}$

\section{Rate of mass transfer:}

The dimensionless rate of mass transfer is given by

$S h=-\left(\frac{d C}{d y}\right)_{y=0}$

\section{RESULTS AND DISCUSSION}

A Numerical study has been carried out on the MHD flow of a Casson fluid. The effects of various physical parameters such as Grashof number, Modified Grashof number, Casson parameter, Magnetic parameter, Permeability parameter, Prandtl number, Heat source, Radiation parameter, Schmidt number and Soret number on velocity, temperature and concentration are discussed with the help of graphs and Skin friction, Nusselt number and Sherwood are also studied with the help of graphs. In Fig.2, the effect of Thermal Grashof number on velocity is presented. As Gr increases, velocity also increases. This is due to the buoyancy which is acting on the fluid particles due to gravitational force that enhances the fluid velocity. A similar effect is noticed from Fig.3, in the presence of modified Grashof number, which also increases fluid velocity. Fig.4, demonstrates that the velocity decreases with an increase in Casson parameter.

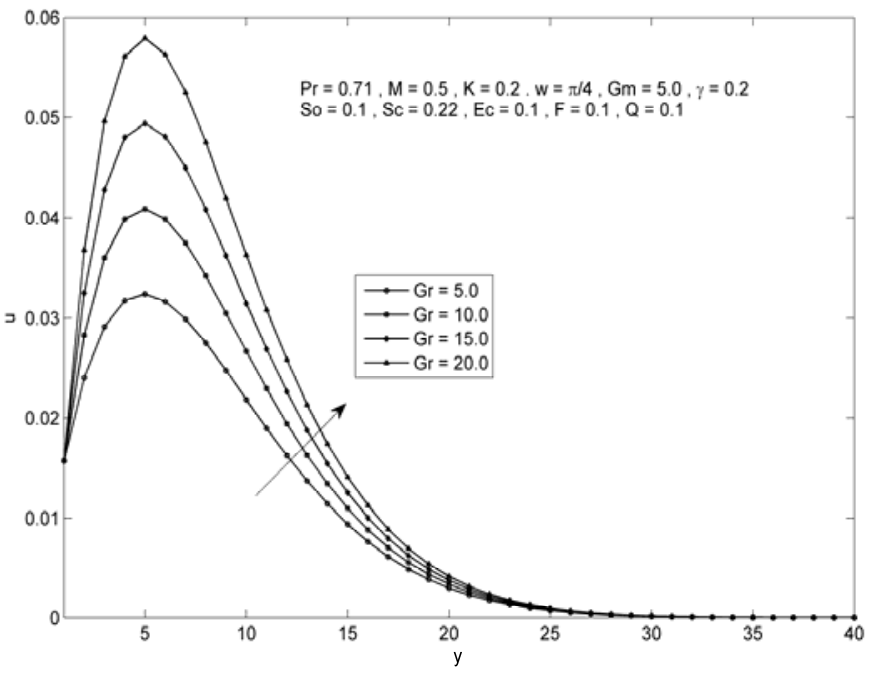

Fig. 2 Effect of Grashof number on velocity

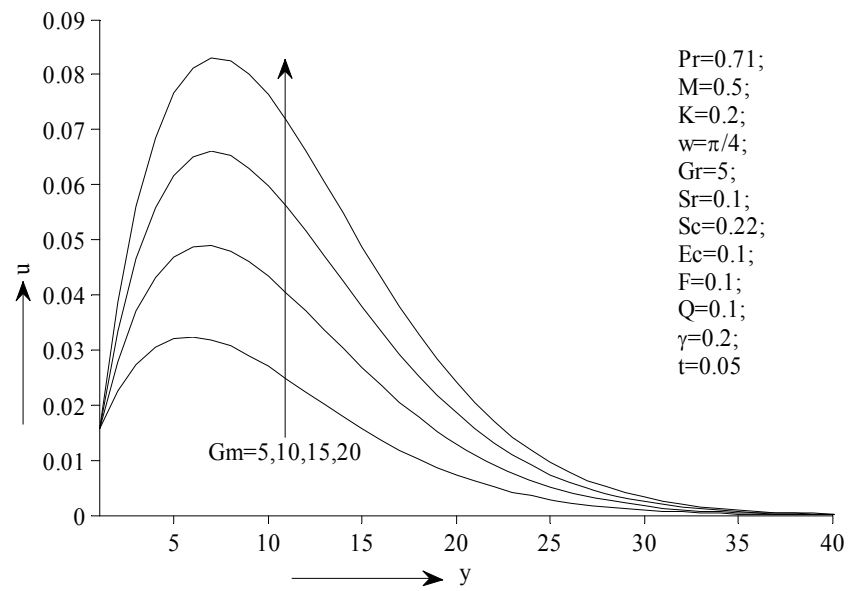

Fig. 3 Effect of modified Grashof number on velocity

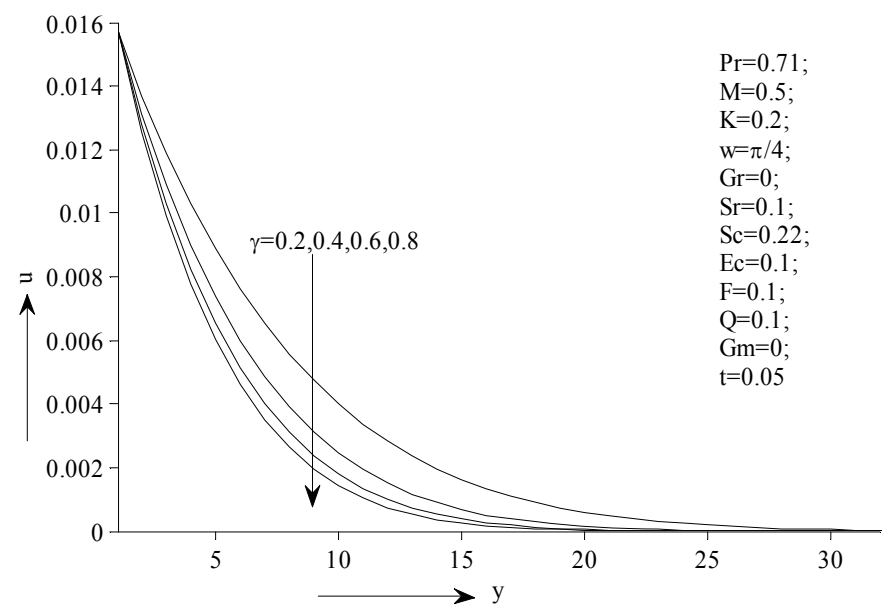

Fig. 4 Effect of Casson parameter on velocity

In Fig. 5, velocity profiles are displayed with the variation in magnetic parameter. From this figure it is noticed that velocity gets reduced by the increase of magnetic parameter. Because the magnetic force which is applied perpendicular to the plate, retards the flow, which is known as Lorentz force. Hence the presence of this retarding 
force reduces the fluid velocity. Fig. 6 shows that the velocity increases with an increase in permeability parameter. This is due to the fact that increasing values of $\mathrm{K}$ reduces the drag force which assists the fluid considerably to move fast. Fig. 7 depicts the variations in velocity profiles for different values of Schmidt number.

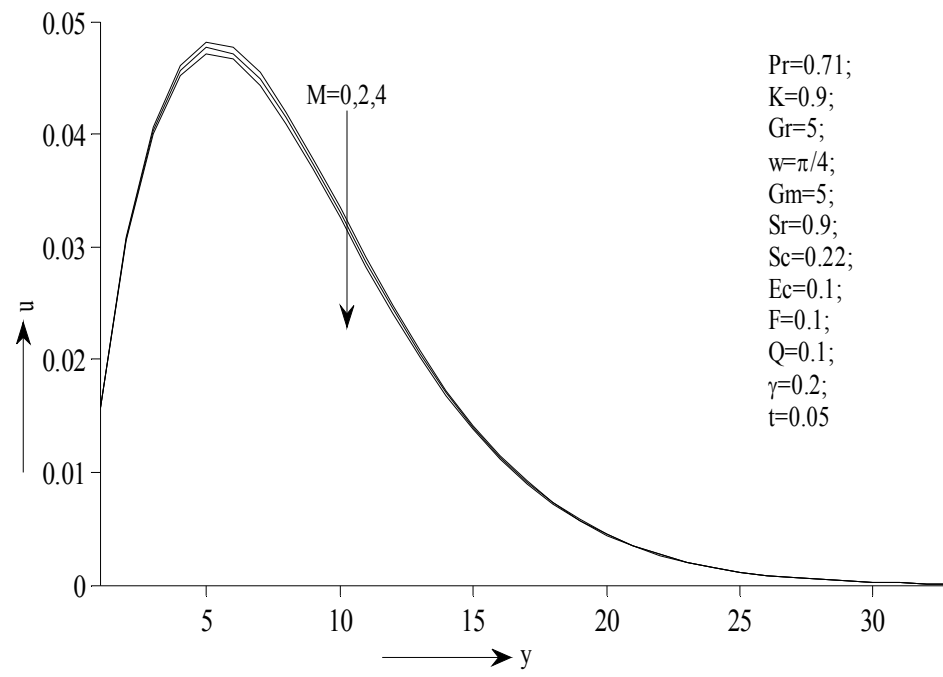

Fig. 5 Effect of magnetic parameter on $u$

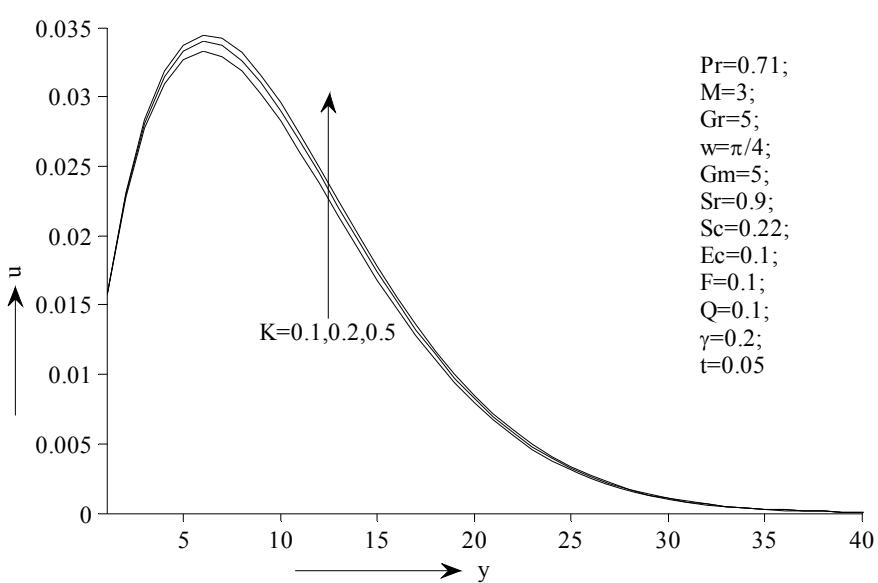

Fig. 6 Effect of permeability parameter on velocity

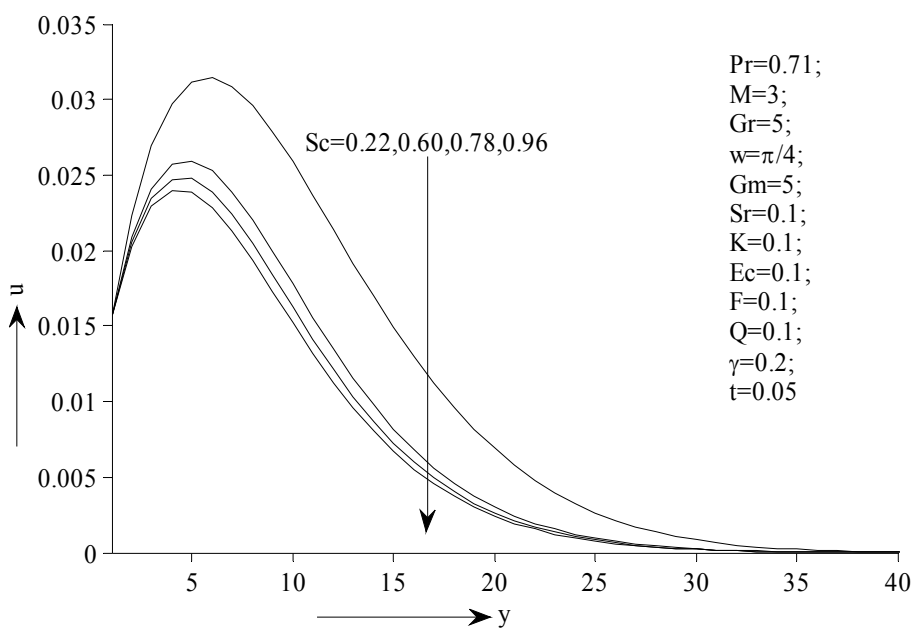

Fig. 7 Effect of Schmidt number on velocity

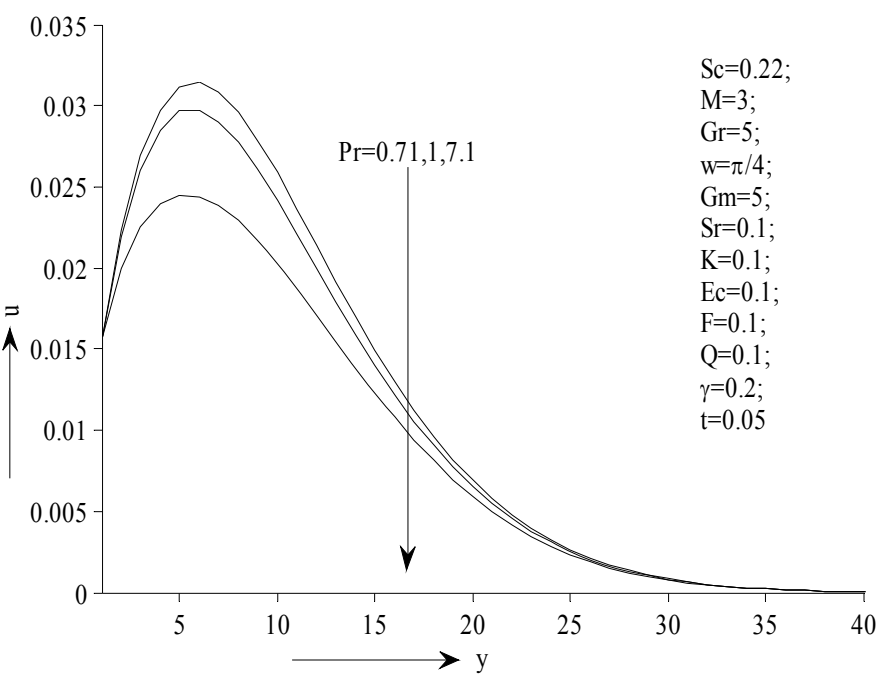

Fig. 8 Effect of Prandtl number on velocity

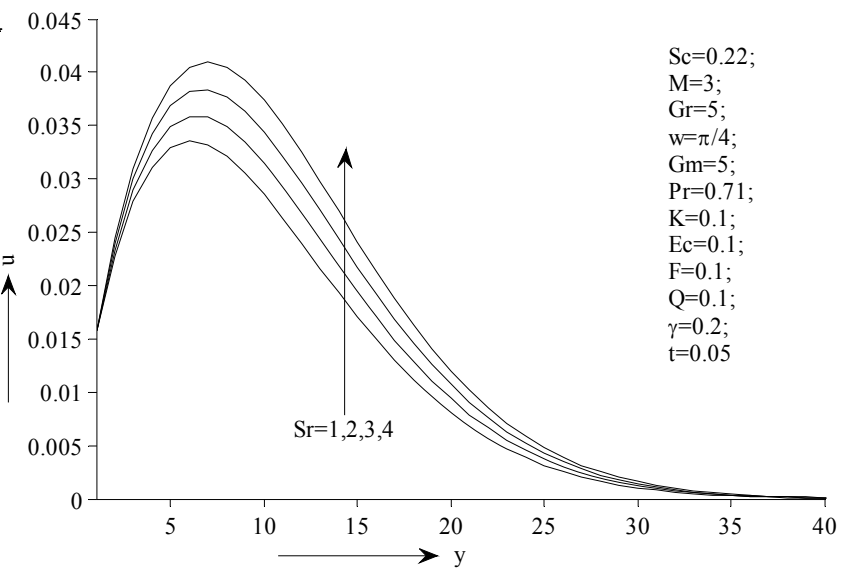

Fig. 9 Effect of Soret number on velocity

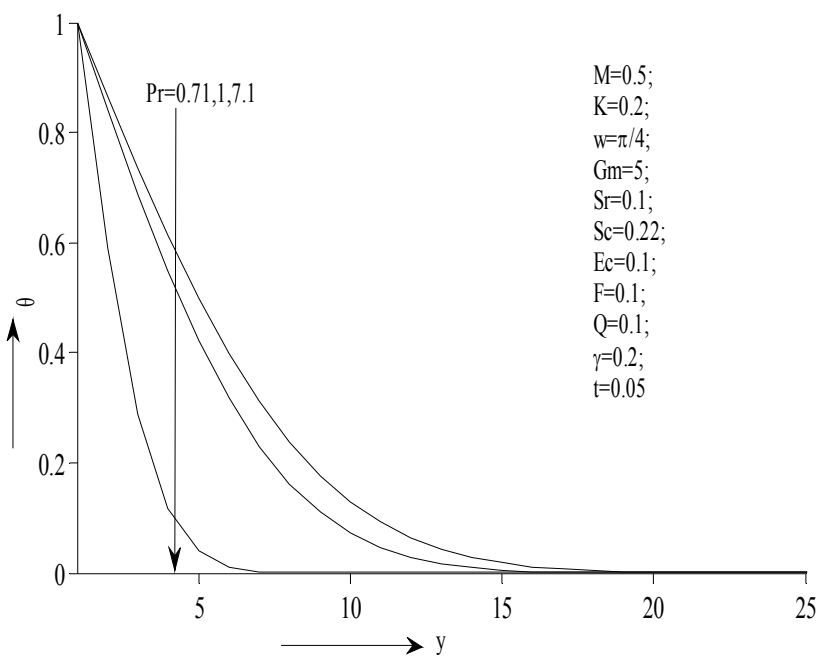

Fig. 10 Effect of Prandtl number on temperature

From this figure it is noticed that, velocity decreases as $\mathrm{Sc}$ increases. Physically it is true that if the concentration increases the density of the fluid increases which results a decrease in fluid particles. Fig. 8 demonstrates that the velocity decreases with an increase in Prandtl number. The velocity profile for different values of $\mathrm{Sr}$ is plotted in the Fig. 9. It is found that the velocity increases with increasing values of $\mathrm{Sr}$. 


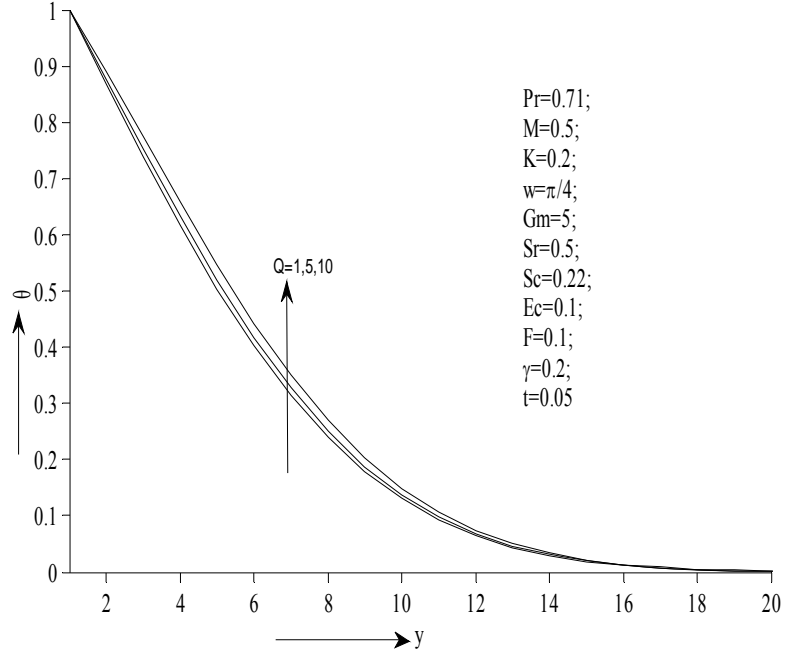

Fig. 11 Effect of heat source on temperature

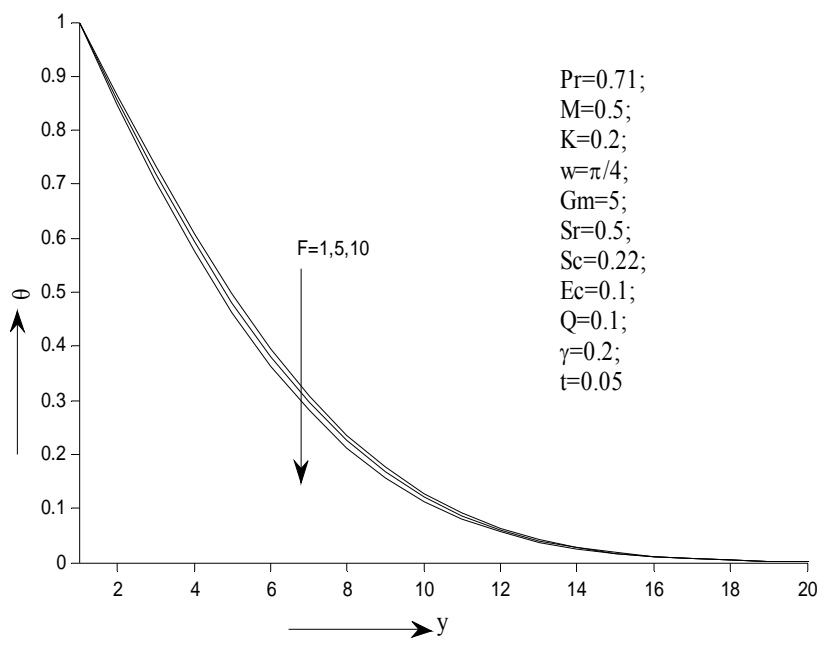

Fig. 12 Effect of Radiation parameter on temperature

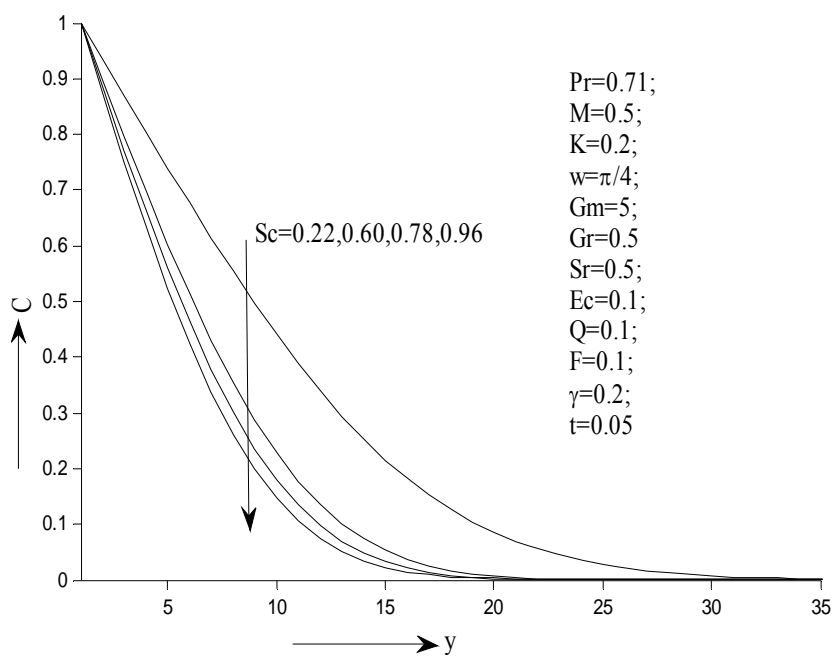

Fig. 13 Effect of Schmidt number on concentration

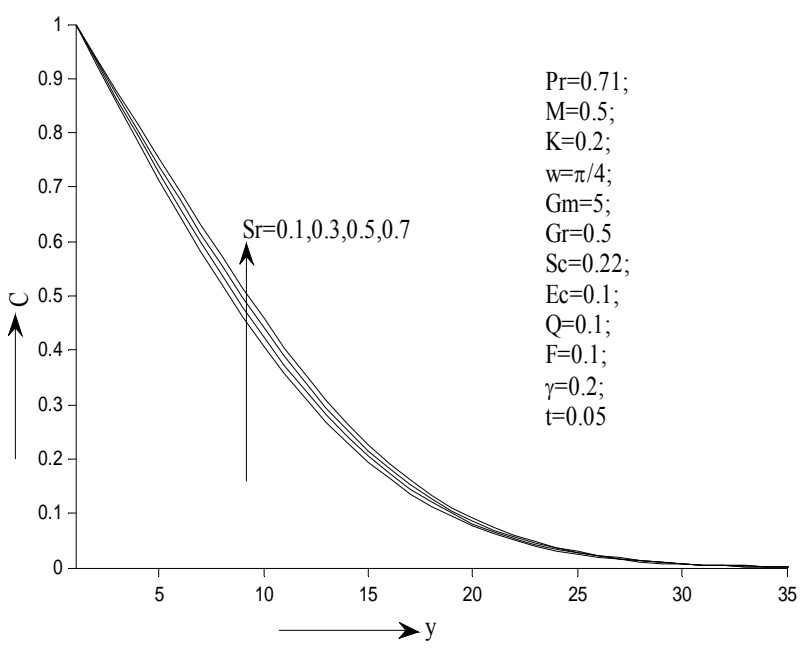

Fig. 14 Effect of Soret number on concentration

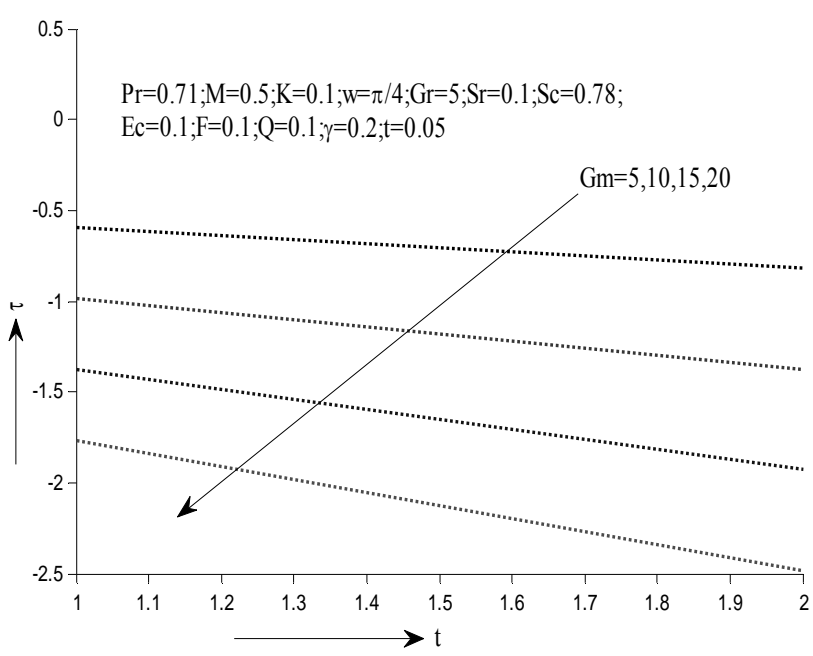

Fig. 15 Effect of modified Grashof number on skin friction

Fig. 10 indicates that a rise in $\operatorname{Pr}$ substantially reduces the temperature in the viscous fluid. It can be found from Fig.10 that the solutal boundary layer thickness of the fluid enhances with the increase of Pr. Fig.11, depicts the effect of heat source on temperature. It is noticed that the temperature is increased by an increase in the heat source by the fluid. The central reason behind this effect is that the heat source causes an increase in the kinetic energy as well as thermal energy of the fluid. The momentum and thermal boundary layers get thinner in case of heat source fluids.Fig. 12 demonstrates the effect of radiation parameter on temperature. It is observed that temperature decreases as radiation parameter increases. Influence of Schmidt number on concentration is shown in Fig.13, from this figure it is noticed that concentration decreases with an increase in Schmidt number. Because, Schmidt number is a dimensionless number defined as the ratio of momentum diffusivity and mass diffusivity, and is used to characterize fluid flows in which there are simultaneous momentum and mass diffusion convection processes. Therefore concentration boundary layer decreases with an increase in Schmidt number. 


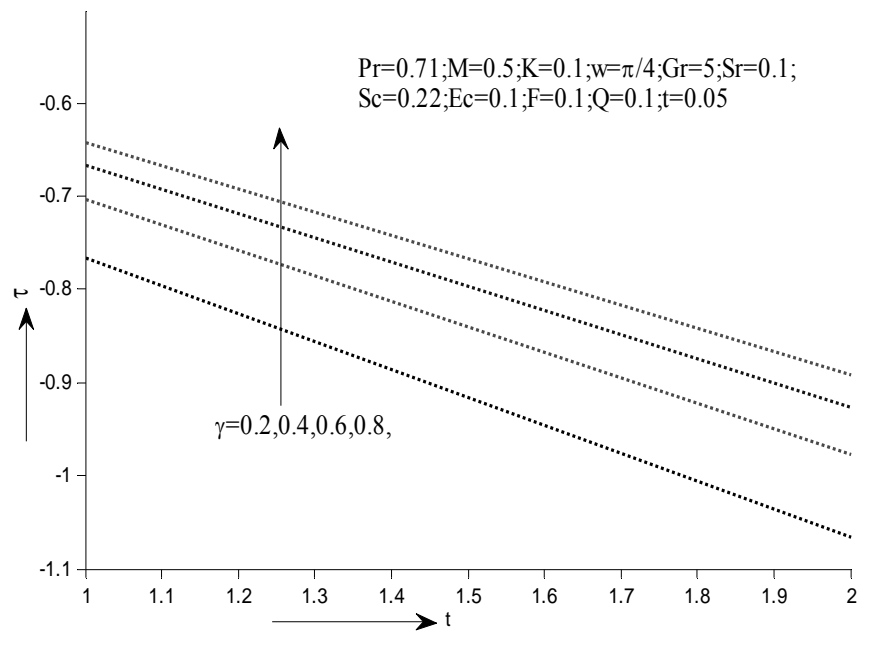

Fig. 16 Effect of Casson parameter on skin friction

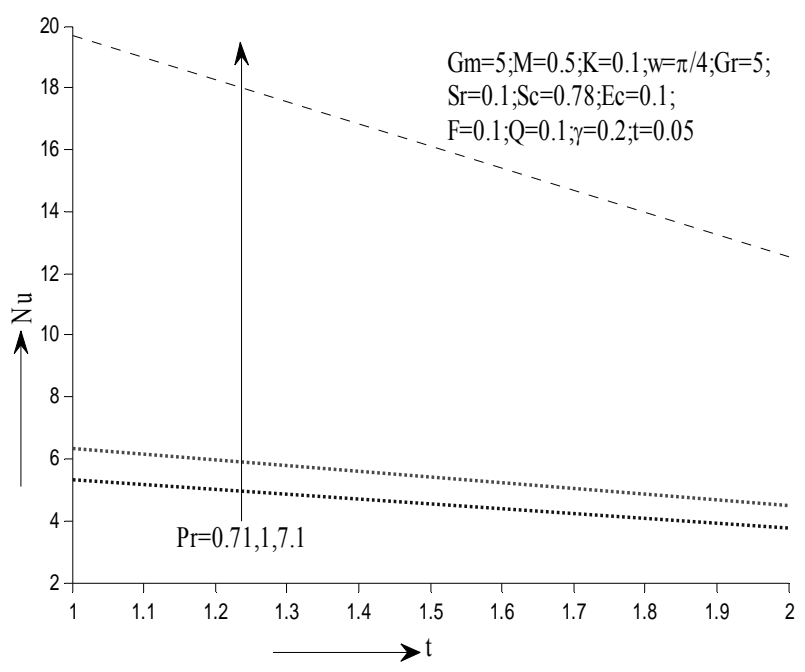

Fig. 17 Effect of Prandtl number on Heat transfer rate

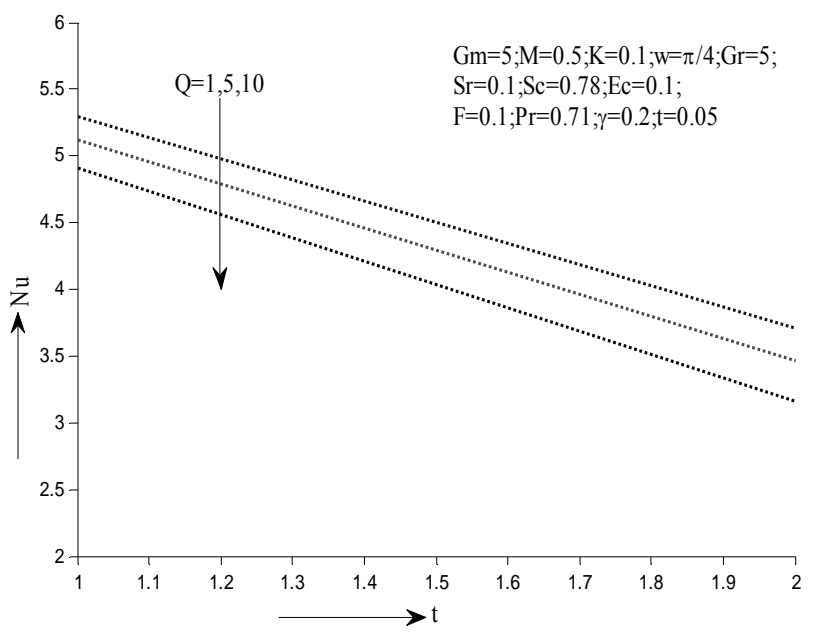

Fig. 18 Effect of heat source on heat transfer rate

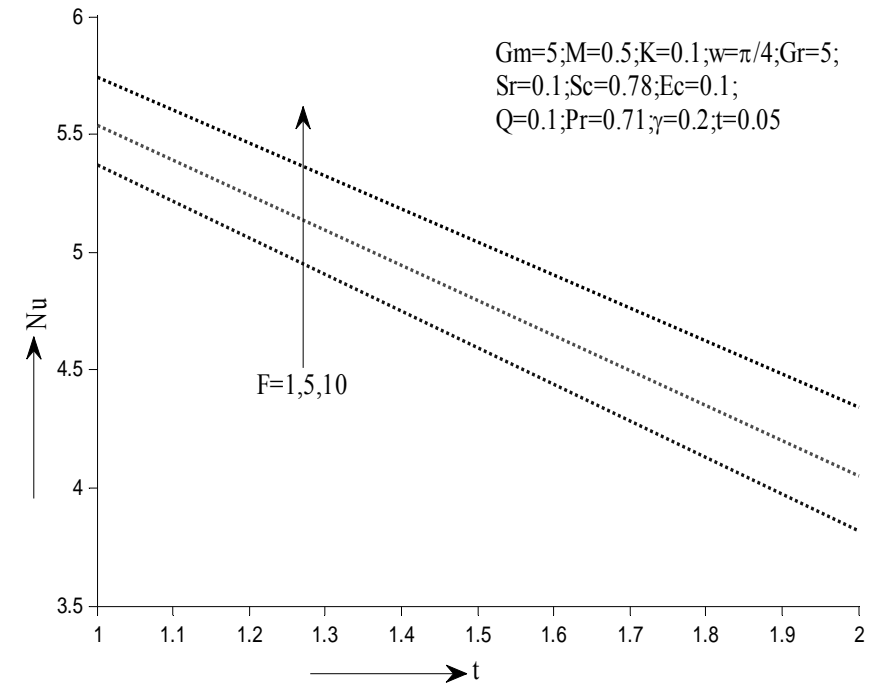

Fig. 19 Effect of radiation parameter on heat transfer rate

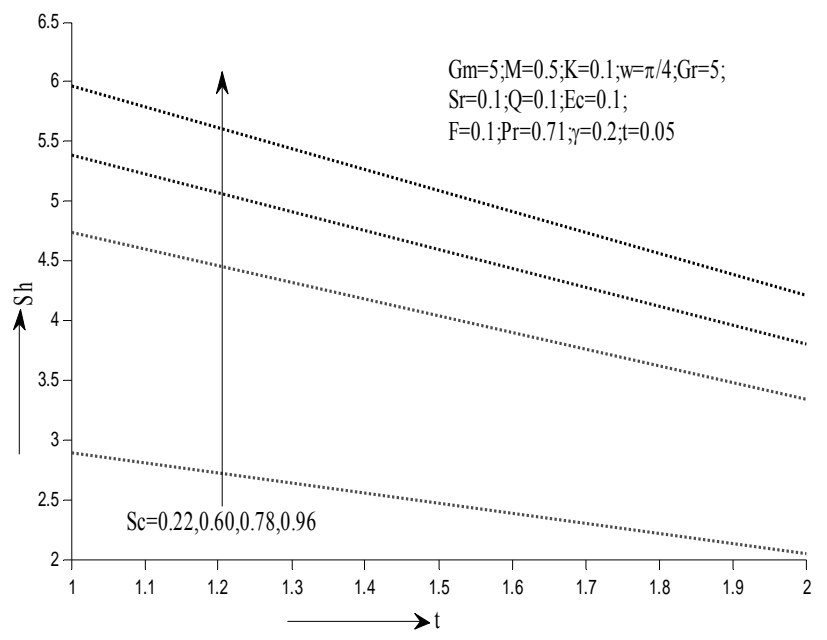

Fig. 20 Effect of Schmidt number on mass transfer rate

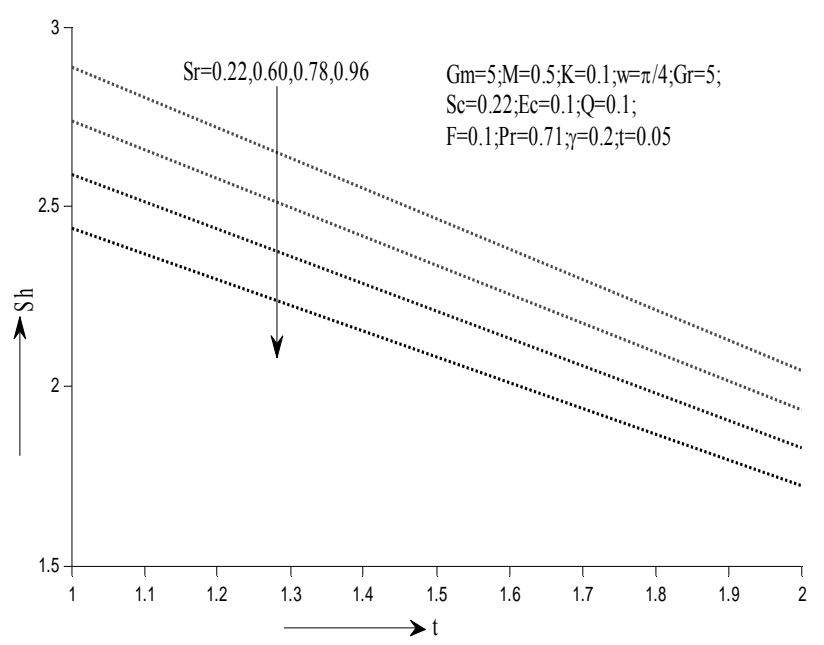

Fig. 21 Effect of Soret number on Sherwood number 
From Fig. 14, we observe that the concentration increases as Soret number increases. Figs. 15 and 16 shows that skin friction decreases with increasing values of Modified Grashof Number, 'Gm', Casson parameter, ' $\gamma$ ', Fig. 17 we observed that the Nusselt number decreases with an increase values of Prandtl number and heat source parameter while it increase with increasing value of radiation parameter. From Fig.20 it is observed that Sherwood number increases with an increase in Schmidt number 'Sc' while it decreases in case of Soret Number 'Sr'.

\section{CONCLUSIONS}

An analysis is performed to investigate the effects of Joule heating and Soret effect (Thermal diffusion) on unsteady, incompressible, electrically conducting radiative heat and mass transfer MHD flow of casson fluid past an infinite vertical plate with constant wall temperature and mass diffusion. The dimensionless governing equations are solved by Finite difference method. The results for velocity, temperature and concentration plotted graphically. And the following conclusions are made:

- As Gr increases, velocity also increases. This is due to the buoyancy which is acting on the fluid particles due to gravitational force that enhances the fluid velocity also it has been happen when modified Grashof number increased.

- It is found that velocity gets reduced by the increase of magnetic parameter it is due to the fact that retarding force drag the velocity while it decreases with an increase in permeability parameter.

- It is interesting note that the solutal boundary layer thickness of the fluid increases as Prandtl number increases. But a reverse effect is found with increase of radiation parameter.

- It is noticed that concentration decreases with an increase in Schmidt number however it increases an increase in soret number.

- skin friction enhances with an a reduction in Modified Grashof Number ' $\mathrm{Gm}$ ' as well as Casson parameter, ' $\gamma$ ', whereas the Nusselt number decreases with an increase in Prandtl number while it increases as radiation parameter increases and finally it is observed that Sherwood number increases with an increase in Schmidt number 'Sc' while it decreases in case of Soret Number 'Sr'.

\section{ACKNOWLEDGEMENTS}

The authors are thankful to the reviewers for their suggestions, which have significantly improved the quality of our research paper.

\section{NOMENCLATURE}

$B_{0}: \quad$ Magnetic field coefficient

C: $\quad$ Species concentration

$C_{f x}: \quad$ Local skin friction coefficient

$C_{p}: \quad$ Specific heat at constant pressure

$C_{w}: \quad$ Wall dimensional concentration

$C_{\infty}: \quad$ Ambient temperature

$C^{*}: \quad$ Dimensional concentration

D: $\quad$ Mass diffusivity

$\mathrm{D}_{1}$ : $\quad$ Thermal diffusivity

$e_{b \lambda:} \quad$ Planck's Constnat

$F: \quad$ Radiation parameter

$g$ : Gravitational acceleration

$G r$ : Grashof number

Gm : $\quad$ Solutal Grashof number

$\mathrm{J} \quad$ : Current density

K : Permeability parameter

\begin{tabular}{|c|c|}
\hline$K_{\lambda w}:$ & Absorption coefficient \\
\hline$N:$ & Dimensionless material parameter \\
\hline$N u_{x}:$ & Local Nusselt Number \\
\hline n: & Scalar constant \\
\hline Pr: & Prandtl number \\
\hline Q: & Heat source parameter \\
\hline $\mathrm{Q}_{0}:$ & Volumetric rate of heat generation or absorption \\
\hline$q_{w}:$ & Heat flux per unit area at the plate \\
\hline R: & Coefficient of chemical reaction \\
\hline$S r$ & Soret effect \\
\hline$t:$ & Dimensionless time \\
\hline$T:$ & Temperature in the boundary layer \\
\hline$T_{w}:$ & Wall dimensional temperature \\
\hline$T_{\infty}:$ & Ambient temperature \\
\hline$u, v:$ & Components of the velocities \\
\hline$x, y:$ & Co-ordinate system \\
\hline \multicolumn{2}{|c|}{ Greek Symbols } \\
\hline$\alpha:$ & Characteristic dimension of the flow fluid \\
\hline$\beta_{T}:$ & Coefficient of volume expansion for heat transfer \\
\hline$\beta_{c}:$ & Coefficient of volume expansion for mass transfer \\
\hline$\kappa:$ & Thermal conductivity of the fluid \\
\hline$\varepsilon:$ & Scalar constant $(<<1)$ \\
\hline$\eta:$ & Dimensionless normal distance \\
\hline$\gamma:$ & Chemical reaction parameter \\
\hline$\mu:$ & Viscosity of the fluid \\
\hline$\rho:$ & Density of the fluid \\
\hline$\sigma:$ & Magnetic permeability of the fluid \\
\hline$v:$ & Kinematic viscosity \\
\hline \multicolumn{2}{|c|}{ Superscripts } \\
\hline ': & Differentiation with respect to ' $y$ ' \\
\hline$*:$ & Dimensional parameters \\
\hline \multicolumn{2}{|c|}{ Subscripts } \\
\hline$w:$ & Wall condition \\
\hline$\infty:$ & Free stream condition \\
\hline
\end{tabular}

\section{REFERENCES:}

Vajravelu, K., and Mukhopadhyay, S., 2013, "Diffusion of Chemically reactive Species in Casson Fluid Flow over an Unsteady Permeable Stretching Surface," J. Hydrodyn. 25, 591-598. http://dx.doi.org/10.1016/s1001-6058(11)60400-x

Dash R. K., Mehta K. N., and Jayaraman G., 1996, "Casson Fluid flow in a Pipe Filled With a Homogeneous Porous Medium," International Journal of Engineering Science. 34(10), 1145-1156. http://dx.doi.org/10.1016/0020-7225(96)00012-2

Nadeem, S., Haq, R.U., Akbar, N.S., and Khan Z.H., 2013, "MHD Three-Dimensional Casson Fluid Flow Past a Porous Linearly Stretching Sheet," Alexandria Engineering Journal, 52, 577-582. http://dx.doi.org/10.1016/j.aej.2013.08.005

Nadeem S., Haq R.U., and Lee, C., 2012, "MHD Flow of a Casson Fluid over an Exponentially Shrinking Sheet," Scientia Iranica, Vol.19, pp.1550-1553.

http://dx.doi.org/10.1016/j.scient.2012.10.021

Pramanik, S, 2014, "Casson Fluid Flow And Heat Transfer Past an Exponentially Porous Stretching Surface in the Presence of Thermal 
Radiation,” Ain Shams Eng. J., 5, 205-212. http://dx.doi.org/10.1016/j.asej.2013.05.003

Hayat, T., Shehzadi SA., Alsaedi A., 2012, "Soret and Dufour Effects on Magneto Hydrodynamic (MHD) Flow of Casson Fluid," Appl Math Mech EnglEd, 33, 1301-12. http://dx.doi.org/10.1007/s10483-012-1623-6

Mustafa M, Hayat T, Pop I, Aziz A. 2011, "Unsteady Boundary Layer Fow of a Casson Fluid due to an Impulsively Started Moving Flat Plate," Heat Transfer. 40, 563-576.

http://dx.doi.org/10.1002/htj.20358

Abdelnaby, M.A., Eldabe, N.T. and Abou-zeid, M.Y., 2006, "Numerical Study of Pulsatile MHD Non-Newtonian Fluid Flow With Heat And Mass Transfer Through a Porous Medium Between Two Permeable Parallel Plates," Ind. J. Mech. Cont. \& Math Sci, 1, 1-15.

Mukhopadhyay. S., 2013, "Effects of Thermal Radiation on Casson Fluid Flow and Heat Transfer over an Unsteady Stretching Surface Subjected to Suction/Blowing," chin. Phys.B, 22(11), article ID 114702.

http://dx.doi.org/10.1088/1674-1056/22/11/114702

Mukhopadhyay, S, De, PR, Bhattacharyya, K, Layek, GC, (2013), "Casson Fluid Flow over an Unsteady Stretching Surface," Ain Shams Eng. J. 4, 933-938.

http://dx.doi.org/10.1016/j.asej.2013.04.004

Shateyi, S, Marewo, G.T., 2014, "Numerical Analysis of MHD Stagnation Point Flow of Casson Fluid, Heat and Mass Transfer Over a Stretching Sheet," In: Balicki J (ed.) Advances in Applied and Pure Mathematics. 128-132, WSEAS, Proceedings of the 7th International Conference on Finite Differences, Finite Elements, Finite Volumes, Boundary Elements (F-and-B '14).

Boyd .J, Buick J. M., and Green S., 2007, “Analysis of The Casson and Carreau-Yasuda Non-Newtonian Blood Models in Steady and Oscillatory Flows Using the Lattice Boltzmann Method," Physics of Fluids. 19, 93, Article ID 093103.

http://dx.doi.org/10.1063/1.2772250

Mernone A. V., Mazumdar J. N., and Lucas S. K., 2002, "A Mathematical Study of Peristaltic Transport of a Casson Fluid," Mathematical and Computer Modelling. 35, 7-8, 895-912. http://dx.doi.org/10.1016/s0895-7177(02)00058-4

Sivagnana Prabhu KK, Kandasamy R, Saravanan R., 2009, “Lie Group Analysis For The Effect of Viscosity And Thermophoresis Particle Deposition on Free Convective Heat and Mass Transfer in The Presence of Suction / Injection". Theoret Appl Mech 36(4), 275-98. http://dx.doi.org/10.2298/tam0904275s
Bhattacharyya K., 2013, "Boundary Layer Stagnation-Point Flow of Casson Fluid and Heat Transfer Towards a Shrinking/Stretching Sheet," Frontiers in Heat and Mass Transfer, 4, 2, Article ID 023003. http://dx.doi.org/10.5098/hmt.v4.2.3003

Pramanik S., 2014, "Casson Fluid Flow And Heat Transfer Past an Exponentially Porous Stretching Surface in Presence of Thermal Radiation," Ain Shams Engineering Journal. 5(1), 205212. http://dx.doi.org/10.1016/j.asej.2013.05.003

Mustafa, M., Hayat, T., Pop, I. and Hendi, A. A., (2012), "StagnationPoint Flow And Heat Transfer of a Casson Fluid Towards a Stretching Sheet," Z. Naturforsch., 67a, p.70. http://dx.doi.org/10.5560/zna.2011-0057

Hayat T, Shehzadi SA, Alsaedi A., 2012, "Soret and Dufour Effects on Magnetohydrodynamic (MHD) Flow of Casson Fluid," Appl Math Mech (English Ed.). 33(10), 1301-12. http://dx.doi.org/10.1007/s10483-012-1623-6

Shehzad SA, Hayat T, Qasim M, Asghar S., 2013, "Effects of mass transfer on MHD flow of Casson fluid with chemical reaction and suction". Braz J Chem Eng. 30(01), 187-95. http://dx.doi.org/10.1590/s0104-66322013000100020

Nadeem. S, Haq R.U, Akbar N.S and Khan Z. H ., 2013, "MHD ThreeDimensional Casson Fluid Flow Past a Porous Linearly Stretching Sheet," Alexandria Engineering Journal,52, 577-582. http://dx.doi.org/10.1016/j.aej.2013.08.005

Mukhopadhyay, S, De, PR, Bhattacharyya, K, Layek, GC, (2013), "Casson Fluid Flow Over an Unsteady Stretching Surface," Ain Shams Eng. J. 4, 933-938.

http://dx.doi.org/10.1016/j.asej.2013.04.004

Makinde OD, Chinyoka T., 2013, "Numerical Investigation of Buoyancy Effects on Hydromagnetic Unsteady Flow through a Porous Channel with Suction / Injection". J Mech Sci Technol. 27(5), 1557-68. http://dx.doi.org/10.1007/s12206-013-0221-9

Kumar,A.G.V., and Vijaya Kumar Varma,S., 2011, “Thermal Diffusion and Radiation Effects on Unsteady MHD Flow Past an Impulsively Started Exponentially Accelerated Vertical Plate with Variable Temperature and Variable Mass Diffusion," Int. J. of Applied Mathematical Analysis and Applications, Vol.6, No.1- 2, pp.169-192.

Kumar, B.R., Sravan Kumar, T., and Vijaya Kumar, A G., 2015. "Thermal Diffusion and Radiation Effects on Unsteady Free Convection Flow In the Presence of Magnetic Field Fixed Relative to the Fluid or the Plate". Frontiers Heat and Mass Transfer, 6, 12, pp. 19.

http://dx.doi.org/10.5098/hmt.6.12 